\title{
A Scientific Approach to Flame Radiation and Material Flammability
}

\author{
JOHN DE RIS \\ Factory Mutual Research Corporation \\ Norwood, Massachusetts 02062, USA
}

\section{ABSTRACT}

The paper briefly reviews our scientific understanding of some of the better understood flammability properties such as ignitability, flame spread, and convective burning to illustrate the utility of practical test method apparatuses for evaluating flammability properties. We then discuss the essential role of flame radiation in controlling hazardousscale burning rates and why we presently think that a fuel's classical smoke-point may indicate its radiative hazard. We then examine in more detail the soot radiation from small laminar flames to illustrate our emerging scientific understanding of flame radiation. Finally, we suggest a possible smoke-point radiation test apparatus suitable for solid fuels.

\section{INTRODUCTION}

The flammability of a material depends on its ease of ignition, ability to propagate a flame, its maximum burning rate per unit surface area and $i t s$ ease of extinguishment. In general each of these processes depends on different thermo-chemical mechanisms which in turn depend on different combinations of fuel properties as well as the geometric arrangement and scale of the fuel in addition to environmental factors. A central goal of fire research is to develop a series of test methods for evaluating those fuel properties which govern a material's flammability so that one can anticipate and control its fire hazard.

It is now widely recognized that no single material flammability test can completely characterize a fuel's flammability. Instead we need to identify a series of tests which measure the various individual fuel properties controlling flammability. We also need sufficient scientific understanding on how these fuel properties influence fire hazards in different practical situations of interest.

Over the past decade we have made remarkable progress by use of computer models in understanding the progress of fire growth and smoke movement in enclosures and even in complex buildings. However, these models generally presume (rather than predict) the growth rate of the originating fire. We cannot predict fire growth rates, because we lack both a full fundamental understanding of flame radiation and we do not have test methods which measure this essential flammability property. 
The present paper briefly reviews our understanding of some of the better understood flammability properties such as ignitability, flame spread, and convective burning to illustrate the utility of practica: test methods for evaluating flammability properties. We then discuss the essential role of flame radiation in controlling burning rates and why we presently think that fuel's classical smoke-point may indicate its radia. tive hazard. We then examine in more detail the soot radiation fror small laminar flames to illustrate our emerging scientific understanding of flame radiation. And finally, we suggest a possible smoke-point radiation test apparatus suitable for solid fuels.

\section{SOME ESTABLISHED FLAMMABILITY TEST METHODS}

a) Ignitability - Around 1960 basic research on ignition shower that the piloted ignition of a solid could be described by a transient conduction model yielding a time to ignition given by

$$
t_{i g}=\begin{aligned}
& \frac{\pi}{4} k_{s} \rho_{s} C_{s} \frac{T_{i g}-T_{\infty}}{\dot{q}^{\prime \prime}} 2 \text {, thermally thick } \\
& \rho_{s} c_{s} a_{s} \frac{T_{i g}-T_{\infty}}{\dot{q}^{\prime \prime}} \quad \text {, thermally thin }
\end{aligned}
$$

where $\dot{q}^{\prime \prime}$ is the net externally imposed heat flux, $\mathrm{T}_{1 \mathrm{~g}^{-\mathrm{T}}}$ is the surfact temperature rise required for inducing significant fuel vaporization an $\mathrm{k}_{\mathrm{S}}, \rho_{\mathrm{S}}, \mathrm{C}_{\mathrm{S}}$ and $\mathrm{d}_{\mathrm{S}}$ are respectively the solid thermal conductivity, density, specific heat and sample thickness. These simple relationship: have readily lead to numerous practical ignition tests for which the time to ignition varies with either the inverse square or inverse first power of applied flux depending on whether the sample is thermally thick or thin. In some cases, such as foamed plastics, thermally thick solids car respond according to the thermally thin formula because of in-depth absorption of the imposed thermal radiation. Because ignition times art sensitive to the wavelength of the imposed radiation it is desirable (bui not always practical) to use a long wavelength infrared radiant source characteristic of fires.

b. Flame Spread - Around 1970 basic research on the spread of: creeping flame over a smooth solid surface showed that the spread rate $V$, can be described by the simple formulas:

$V=$

$$
\frac{{ }_{g} \rho_{g} C_{g} V_{g}}{k_{s} \rho_{s} C_{s}} \frac{T_{f}-T_{\infty}}{T_{i g}-T_{\infty}}{ }^{2} \text {, thermally thick }
$$

$$
\frac{\sqrt{2} k_{g}}{\rho_{s} C_{s} d_{s}} \quad \frac{T_{f}-T_{\infty}}{T_{i g}-T_{\infty}} \text {, thermally thin }
$$

where $T_{f}-T_{\infty}$ is the flame temperature rise above ambient and $V_{g}$ is the characteristic buoyancy driven gas-phase velocity near the leading edg of the creeping flame, while $\mathrm{kg}_{\mathrm{g}}, \mathrm{p}_{\mathrm{g}}$ and $\mathrm{C}_{\mathrm{g}}$ are respectively the therma: conductivity, density and specific heat of the gas phase. More recent research has shown how these spread rates are reduced when local chemica: extinction occurs at the leading edge. Also experiments indicate a con. siderable increase in creeping spread rates with increasing surfact roughness. 
A comparison of the above flame spread formulas with the previously mentioned ignition relations suggest the interpretation of the flame spread process as a continuous sequence of ignitions for which the creeping flame provides its own local ignition heat flux. This similarity has been exploited by Quintiere and others who correlate ignition times and creeping flame spread rates for a range of external heat fluxes. Such measurements can be made for practical materials on a standard ASTM-E162 apparatus which subjects a material sample to a spatially decreasing heat fiux.

c. Convective (Non-Radiative) Burning - During the 1950's and $1960^{\circ} \mathrm{s}$ f undamental theoretical studies on mass transfer and combustion showed that the burning rate per unit surface area of a solid in the absence of flame radiation can be described by

$\dot{m}^{\prime \prime} \cong \frac{h^{(0)}}{C_{g}} \ln (1+B)$

where $\dot{m}^{\prime \prime}$ is the mass transfer rate per unit area, $\mathrm{n}^{(0)}$ is the classical convective heat transfer coefficient associated with the geometry in the absence of mass transfer, $C_{g}$ is the gas specific heat, and $B$ is the mass transfer driving force which, in the case of convective burning, is given by the ratio

$B=\frac{\text { Heat release per unit mass of oxidant consumed }}{\text { Heat required to vaporize unit mass of fuel }}$

The numerator in the above expression is generaily quite insensitive to the specific chemistry of typical organic fuels. Thus the mass transfer $\mathrm{d} r$ iving force and consequently the mass transfer rate $\dot{\mathrm{m}}^{\prime \prime}$ depend primarily on the heat of gasification.

Around 1970 this simple result was verified for a variety of smallscale burning situations in which the flames happened to be too small to produce significant flame radiation. Flushed with our apparent sense of success at predicting burning rates several rate-of-heat-release-tests were developed to measure the effective heat of vaporization of practical fuels. Typically such tests impose various levels of external radiative heat flux onto the material sample and measure either: 1) the mass transfer rate by weight loss or 2) the rate-of-heat-release by combustion through the method of oxygen depletion (which exploits the above mentioned proportionality of heat release to oxygen consumed for organic fuels). Typically these tests ignore the heat feedback from the flanes to the fuel surface because it is generally considerably smaller than the imposed external radiant heat flux.

Such rate-of-heat-release tests produce valuable fuel property data. For example Pagni $(1)$ and Delichatsios $(2)$ have shown that flame heights correlate very closely with the rate-of-heat-release in both laminar and turbulent situations. Unfortunately, as we discuss below, one cannot infer burning rates of hazardous-scale fires from merely the small-scale rate-of-heat-release tests because they are insensitive (by design) to the flame's own radiation.

\section{RADIATION FROM TURBULENT FLAMES}

During the 1970's careful experimental measurements (27) of burning solid fuels revealed that radiative heat transfer from flames generally dominates convective heat transfer for flames larger than - say - 0.20 
meters. This important finding has helped explain why the flammabilit: rankings of various fuels are so different at large-scales as compared t: small-scales. The burning processes are controlled by fundamentally dif. ferent heat transfer mechanisms and consequently depend on different fue properties. Small-scale flames have insufficient heated matter (optica: depth) to provide significant radiative heat feedback to the vaporizin fuel surface. On the other hand the enhanced radiation from largel flames causes increased mass transfer rates and a significant decrease il convective heat transfer due to convective blowing awgy from the surface This switch-over in burning mechanism was illustrated 3 ) by comparing the pool fire burning rates of four noncharring plastic fuels: polyoxymethy. lene (POM), polymethylmethacrylate (PMMA), polypropylene (PP) and poly. styrene (PS). These fuels have similar B-numbers $(1.23,1.57,1.16$ anc 1.44, respectively) and correspondingly similar small-scale mass transfer rates. However, the sootiness of their flames increases strongly il their listed order so that their theoretical heat release rate increase appreciably at larger-scale, e.8 for $30.5 \mathrm{~cm}$ square pools, in the sequence $9.34,24.8,34.3$ and $53.7 \mathrm{~kW}$ ). The increase in heat release rat is very sensitive to the sootiness of the flames, because the positivt radiative heat feedback enhances the burning rate which then increase: the flame volume, mean beam length and, in turn, radiative heat feedback.

Typically, about $80 \%$ or more of the radiation from luminous flames i: emitted by soot while the remaining $20 \%$ of the radiation comes from the hot gases such as $\mathrm{CO}_{2}, \mathrm{H}_{2} \mathrm{O}, \mathrm{CO}$ and unburned hydrocarbons. Modak (4) has developed a convenient and rapid computer program for accurately calcu. lating the radiation along a ray through a homogeneous isothermal ga: including soot. Crosshandler ${ }^{(5)}$ and Modak $(6)$ then extended these calcu. lation procedures to nonhomogeneous nonisothermal situations and demon. strated good experimental agreement using time averaged properties for turbulent flames. Modak $(7)$ and others have also shown that the use of Hottel's $(8)$ mean beam length approximations together with zone modelin of major gas volumes generally provide accurate analytical or numerica: treatment of seometric effects. We thus have available a solid theoreti. cal framework for predicting flame radiation provided one can estimat the radiation temperatures and soot volume fractions. Such knowledge of flame properties remains as our principal research challenge and is the topic of the rest of this paper.

Numerous measurements of the total radiation from buoyant turbulent fuel jets have shown that the radiant fraction of the heat release, $x_{R}$ : is independent of the overall heat release rate and depends only on the thermo-chemical nature of the fuel and surrounding ambient oxidant. If is speculated that this independence of $x_{R}$ on $Q$ is due to the fagt that for turbulent fuel jets whose characteristic Froude number $E$ is a constant for purely buoyant jets ${ }^{(9)}$. Final molecular mixing and combustior takes place at this Kolmogorov microscale.

The radiation from turbulent flames increases strongly with ambient oxygen concentrations because of increasing soot volume fractions. Flames in vitiated atmospheres have reduced radiant fractions $(10)$. For example, the radiant fraction from a $30 \mathrm{~cm}$ diameter PMMA pool fire decreases from 0.36 at an ambient concentration of $20.9 \% \mathrm{O}_{2}$ to 0.25 at 18 ; ambient $\mathrm{O}_{2}$. The measured flame radiation temperatures are relativelj insensitive to such reductions in ambient oxygen concentrations because of the competing effects of reduced adiabatio stoichiometric flame tem- 
peratures and reduced radiant heat loss due to significantly lower soot volume fractions.

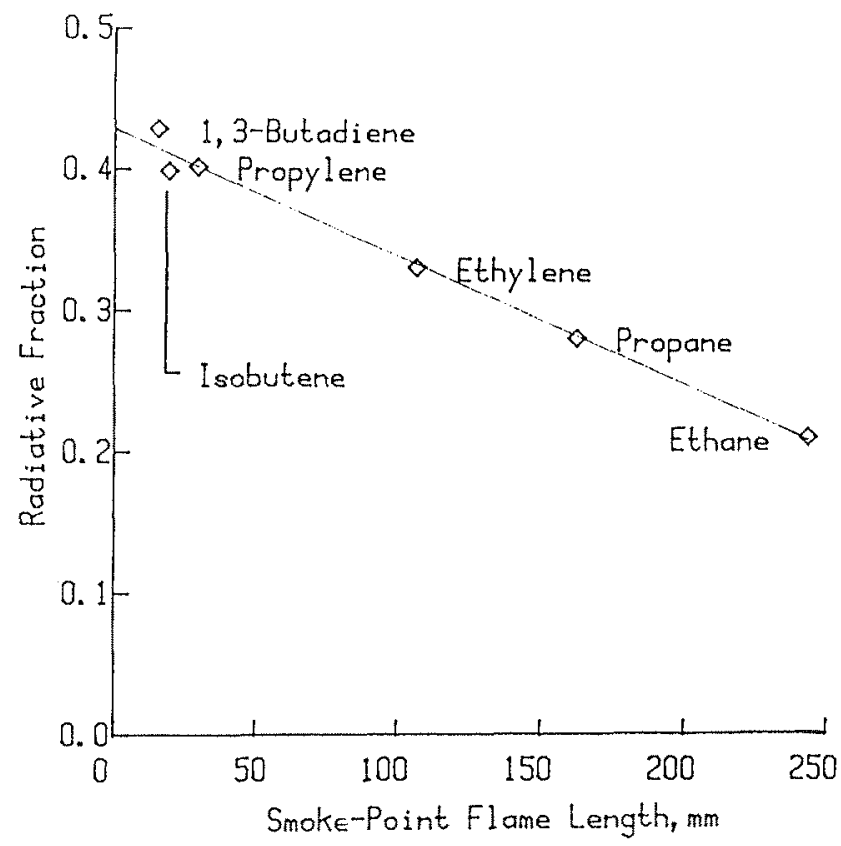

Fig. 1: Radiative fraction $x_{R A D}$ for turbulent fuel-jet flames of various hydrocarbon fuels vs. Smoke-point laminar flame length $\mathrm{L}_{\mathrm{s}}$. Data for $L_{s}$ taken from Ref. 14.

Figure 1 shows Markstein's (11) recent measurements of radiative fractions from turbulent buoyant fuel jets for various hydrocarbon fuels. Here they are plotted against the classical laminar smoke-point flame heights for the respective fuels. The fuel smoke-point is a measure of its propensity for soot formation. It is defined as the maximum laminar diffusion flame height which just does not release smoke at the flame tip. Sooty fuels have lower smoke-point heights because they lose so much heat by radiation that their flames rapidly cool-off preventing soot oxidation at the flame tip. As can be seen in Eigure 1, very sooty fuels have radiant fractions clustering around a maximum of $43 \%$, whereas less sooty fuels such as methane have radiant fractions of less than $20 \%$. Such a twofold change in radiant fraction can have dramatic effects on solid fuel burning rates because of the previously mentioned positive heat feedback role of radiation.

Figure 2 shows Markstein's (12) measurements of the peak soot absorption-emission coefficient (proportional to soot volume fraction) for $0.38 \mathrm{~m}$ diameter pool fires having the same $50 \mathrm{~kW}$ heat release rate and identical fluid flow fields. Once again we see a correlation with the classical smoke-point values. 


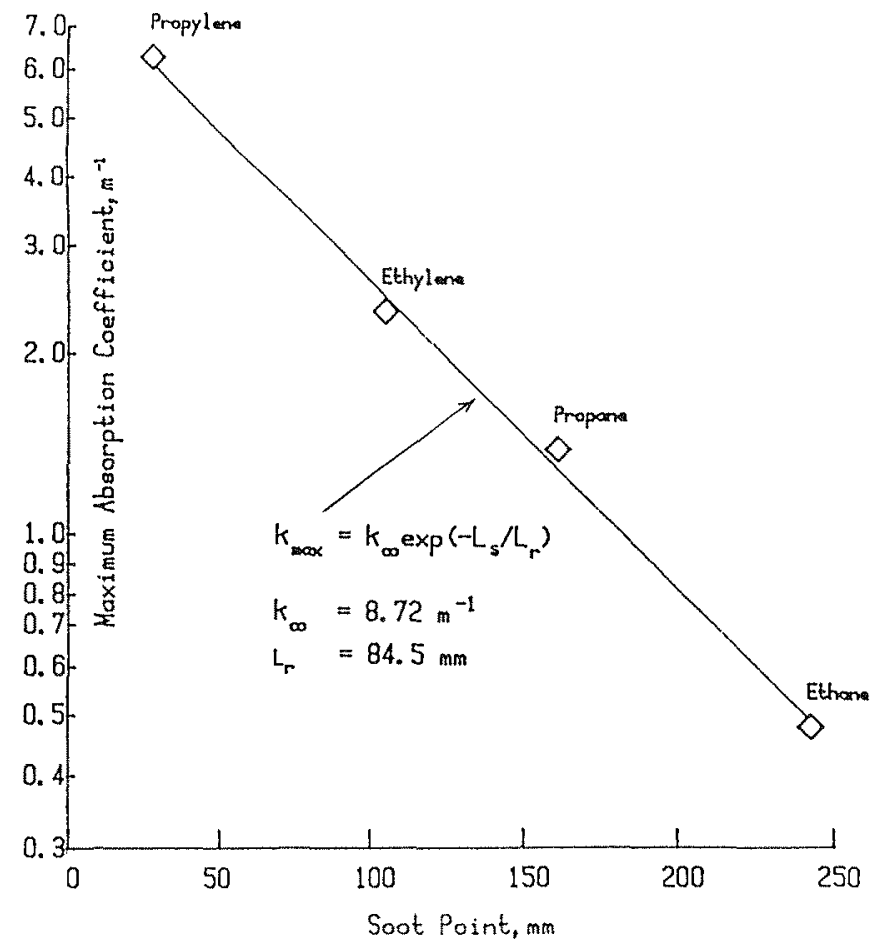

Fig. 2: Maximum absorption coefficient for vertical centerline traverse: of $381-\mathrm{mm}$ dia $50 \mathrm{~kW}$ fires vs soot-point flame length of lamina diffusion flames (values of $\mathrm{L}_{s}$ taken from Ref. 14).

These two empirical correlations suggest that a fuel's laminar smoke point value apparently has some fundamental relationship to a fuel' large-scale radiation and consequently its large-scale fire hazard. W also have some suspicion that the smoke-point values will correlate th smoke and $\mathrm{CO}$ output of a fire; however, this has not yet been experiment aliy confirmed.

\section{RADIATION FROM BUOYANT LAMINAR FLAMES}

To gain deeper fundamental understanding of the relationship of flam radiation and smokempoint, we shall now review some recent results fo laminar buoyant flames.

a) Laminar Flame Heights - We first shall derive a general formul for the height of a small buoyant laminar flame issuing from a circula orifice. Experiments show that the flame height is proportional to th fuel supply rate and independent of the orifice diameter. In general fo buoyant laminar boundary layer flows the characteristic upward velocity $u_{f}$, and characteristic flame radius $r_{f}$, adjust themselves to satisfy th momentum and continuity equations resulting in approximately equal buoy ancy, inertia and viscous forces per unit height. Define the forc ratios 
$F^{2}=\frac{\left[\rho_{f} u_{f}^{2} \pi r_{f}^{2} / l_{f}\right]}{\left[\left(\rho_{\infty}-\rho_{f}\right) g \pi r_{f}^{2}\right]}=\frac{\rho_{f} u_{f}^{2}}{\left(\rho_{\infty}-\rho_{f}\right) g_{f}}$

$R=\frac{\left[\rho_{f} u_{f}^{2} \pi r_{f}^{2} / l_{f}\right]}{\left[\rho_{f} v_{f}\left(u_{f} / r_{f}\right) 2 \pi r_{f}\right]}=\frac{u_{f} r_{f}^{2}}{2 v_{f} l_{f}}$

where $\ell_{f}, v_{f}$ and $\rho_{f}$ are respectively the overall flame length, $f$ lame kinematic viscosity and flame density. We anticipate that both $F^{2}$ and $R$ are of order of unity for our buoyancy controlled flames. Solving for $u_{f}$ and $r_{f}$, one has

$u_{f}=\left[F\left(\rho_{\infty}-\rho_{f}\right) g l_{f} / \rho_{f}\right]^{1 / 2}, r_{f}=\left[4 R^{2} v_{f}^{2} l_{f} \rho_{f} / F\left(\rho_{\infty}-\rho_{f}\right) g\right]^{1 / 4}$

showing that $u_{f}$ and $r_{f}$ scale respectively with the second and fourth roots of height as is characteristic of upward laminar buoyant flows.

Approximating the diffusion flame shape by a right circular cylinder, one obtains the overall (undiluted) fuel mass consumption rate, $\mathrm{M}_{F}$, as

$\dot{M}_{F}=\dot{m}_{F}^{*} 2 \pi r f_{f}^{l}$

Here $\dot{m}_{F}^{\prime \prime}$ is the mean fuel mass consumption rate per unjt flame area, which can be estimated from the variable property solution $(9)$ for a planar diffusion flame in a flow field undergoing a uniform straining deformation, $u_{f} / \ell_{f}$, given by

$\dot{\mathrm{m}}_{\mathrm{F}}^{\prime \prime}=\left.\rho_{\mathrm{f}} \mathrm{D}_{\mathrm{f}} \frac{{ }^{Y_{F}}}{\partial r_{\mathrm{f}}}\right|_{\mathrm{r}_{\mathrm{f}}}=\frac{Y_{F T}}{\mathrm{~s}} \rho_{\mathrm{f}}\left(u_{\mathrm{f}} D_{\mathrm{f}} / 8 \ell_{\mathrm{f}}\right)^{1 / 2} \mathrm{G}(\mathrm{s})$

where $Y_{F T}$ is the mass concentration of fuel issuing from the burner port, $s=Y_{F T} \nu_{O}^{\prime M} O^{\prime} Y_{O \infty} \nu_{F}^{t}{ }_{F}$ is the stoichiometric mass of oxidant required by unit mass of burner gas, $D_{f}$ is the species diffusivity, while $G(s)$ is a weak function of $s$ equal to $5 \pm .5$ for $6 \leqq s \leqq 15$.

Solving for $l_{f}$ between Eqs. (2) and (3), and then substituting from Eqs. (1a) and ( $1 b)$ for $u_{f}$ and $r_{f}$, one obtains the general equation for

$\ell_{\mathrm{f}}=\frac{\dot{\mathrm{M}}_{\mathrm{F}}^{\mathrm{S}}}{\pi \mathrm{Y}_{\mathrm{FT}} \mathrm{G}(\mathrm{s}) \rho_{\mathrm{f}}\left(\mathrm{D}_{\mathrm{f}} \nu_{\mathrm{f}} R\right)^{1 / 2}}=\frac{\dot{\mathrm{M}}_{\mathrm{F}} \mathrm{s}}{\pi \mathrm{Y}_{\mathrm{FT}} \mathrm{G}(\mathrm{s}) \rho_{\infty}\left(D_{\infty} \nu_{\infty} R\right)^{1 / 2}}\left(\frac{\mathrm{T}_{\mathrm{T}}}{\mathrm{T}_{\mathrm{f}}}\right)^{3 / 4}$,

after considering the well-known temperature dependence, $\frac{D_{f}}{D_{\infty}}=\frac{\nu_{f}}{\nu_{\infty}}=\left(\frac{T f}{T_{\infty}}\right)$. Roper (13) obtained a similar formula with $G(s)$ replaced by $4 \operatorname{sen}(1+1 / s)$ for the flame height above a circular port. Note that $M_{F}$ is the supply rate of actual fuel and that $S / Y_{F T}$ is independent of $Y_{F T}$ so that ${ }_{f}$ is independent of $\mathrm{Y}_{\mathrm{FT}}$ except very weakly through $\mathrm{G}(\mathrm{s})$. This formula with
$\mathrm{R}=1$ agrees within 5 percent with the available experimental data $(74-17)$ involving a wide range of fuel and oxidant compositions, thus justifying the assumptions underlying Eqs. (1a, 1b). Although neither $g$ nor $F$ appear in the flame height formula, its assumptions presuppose a buoyancy driven boundary layer flow. Thus it is not valid at zero $g$. 
b) Soot Scaling Relationships - Recently Markstein and de Ris $(1 \varepsilon$ measured the flame absorption and soot absorption cross-sections per uni height for buoyant laminar flames from ethylene and propylene which hav significantly different smoke-point values as seen in Figure 1 . Thes data are correlated in Figure 3 for soot plus gas radiation, and in $F i \xi$ ure 4 for soot alone. For all flames, soot cross-sections correlate i the lower soot- formation regions. For flame heights less than tr smoke-point values, the soot cross-sections also correlate in the uppe soot-oxidation region. For flame heights above the smoke-point valut the correlations break down because the radiant heat loss from the flame cause a reduction in soot oxidation rates and a release of unburned sor from the flame tip.

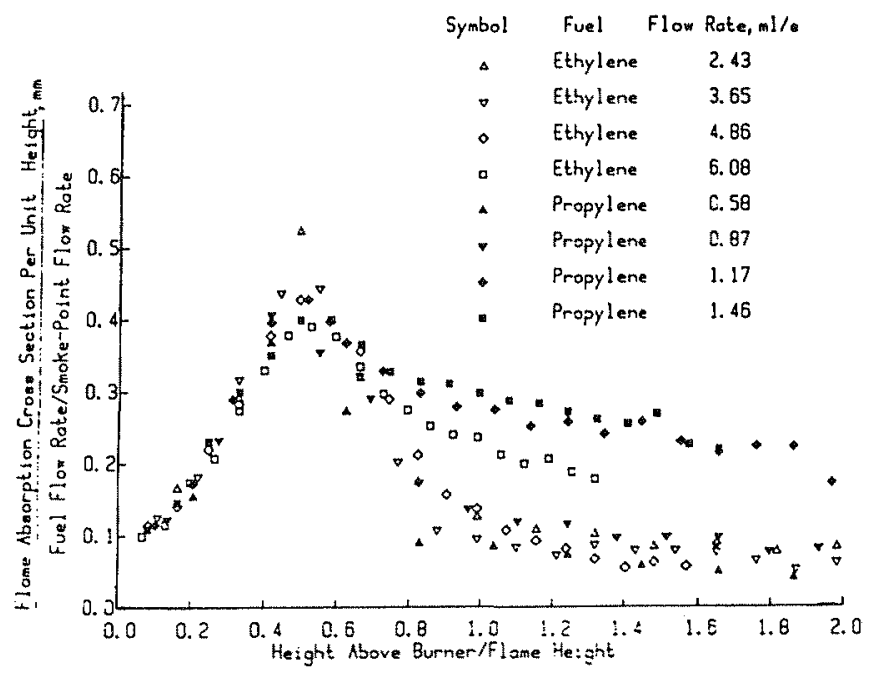

Fig. 3: Normalized plot of spectrally flat absorption cross sections $f c$ laminar diffusion flames

This study also reveals that at a helght equal to the smoke-poir flame length, the flame temperature is $1600 \mathrm{~K}$ for both fuels. Apparentls soot oxidation rates are significantly reduced at this temperaturt Olson (19) also found that the characteristic flame temperatures of hydre carbon fuels are nearly identical for flames at their smoke-point condj tion.

Figures 3 and 4 show that the peak values of soot absorption per unj height, $a_{s}=\pi k r_{f}^{2}$ increase linearly with fuel flow rate and have tr same peak value ( $-1 \mathrm{~mm}$ ) for both ethylene and propylene at their respec tive smoke-points, that is

$\left(\pi k_{\mathrm{s}} \mathrm{r}_{\mathrm{f}}^{2}\right)_{\text {peak }}-\ell_{\mathrm{f}} / \ell_{\mathrm{fs}}$

Since both $\underset{1 / \mathrm{f}}{\mathrm{r}}{ }^{2}$ and the characteristic flow time, $\tau_{\mathrm{f}}=\ell_{\mathrm{f}} / \mathrm{u}_{\mathrm{f}}$ are propor tional to $l^{\frac{1}{2}}$, the data suggest the following scaling of the soot for mation rate

$\frac{D k_{s}}{D t}=\frac{\left(k_{s}\right) \text { peak }}{\tau_{f}}=\frac{\left(k_{s} r_{f}^{2}\right) \text { peak }}{\tau_{f} r_{f}^{2}}-\frac{\left(\ell_{f} / l_{f s}\right)}{\ell_{f}}-1 / l_{f s}$ 


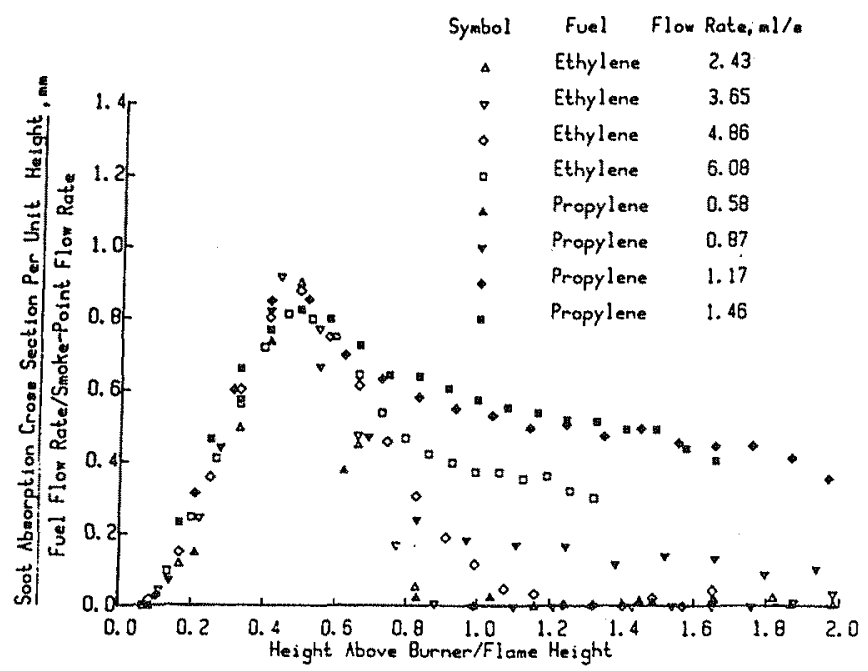

Fig. 4: Normalized plot of monochromatic absorption oross sections for laminar diffusion flames

which is independent of the flame height, $\ell_{f}$, for a given fuel. Thus the overall soot formation rate scales in a simple manner despite the considerable complexities of the detailed 195 ocesses. Furthermore, for flames at their smoke points $\tau_{f}=\tau_{f s}-l_{f s}{ }^{172}$ provides

$\left(k_{s}\right)_{\text {soot-point }} \approx \tau_{f s} \frac{D k_{s}}{D t}-1 / l_{f s}{ }^{1 / 2}$ which is consistent with $\left(k_{s} r^{2}\right)_{\text {peak }}$ being equal at the respective smoke
points.

This result allows one to estimate the overall radiative fraction, $\chi_{\mathrm{R}}$, from these flames at their respective smoke points.

$\chi_{\mathrm{RS}}=\dot{Q}_{\mathrm{R}} / \dot{Q}_{\mathrm{TOT}}=4 \pi \mathrm{k}_{\mathrm{s}} \sigma\left(\mathrm{T}_{\mathrm{fs}}^{4}-\mathrm{T}_{\infty}^{4}\right)\left(\pi \mathrm{r}_{\mathrm{f}}^{2} \ell_{\mathrm{f}}\right) / \dot{M}_{\mathrm{F}} \Delta \mathrm{H}_{\mathrm{C}}$

where $4 \pi k_{s} \sigma\left(T_{f s}^{4}-T_{\infty}^{4}\right)$ is the effective radiation per unit flame volume and $\left(\pi r_{f}^{2} l_{f}\right)$ is the flame volume. Since: 1) the flame temperatures $T_{f}$ are the same at the respective smoke points; 2$) \ell_{f} \sim \dot{M}_{F}$ for similar flame temperatures and stoichiometries; and 3$)\left(k_{s} r_{f}\right)$ peak is the same for fuels at their respective smoke points, we anticipafephat the two fuels, ethylene and propylene, should have identical overall radiative fractions at their smoke points. This result was predicted prior to measurement of the overall radiative fractions from laminar diffusion flames. Its confirmation, as described below, adds considerable reinforcement to the concept of fundamental role of the smoke- point for characterizing both soot-formation rates and flame radiation.

c) Radiative Fraction from Laminar Flames - Figure 5 shows Markstein's (1+) correlation of the overall radiative fraction for four olefin fuels versus their heat release rate, $\dot{Q}_{T}$, normalized by its smoke-point value $\dot{Q}_{T S} \cdot \quad$ [Here $\dot{Q}_{L}$ is a small empirical correction for: 1) heat loss 
to the fuel holder, and 2) blue zone quenching taking place at the flan base. Theoretical arguments, data and visual observations suggest the this small correction is independent of the fuel supply rate.] This re markable correlation spans a wide range of heat release rates. We not that the four fuels have similar adiabatic stoichiometrio flame tempera tures $(-2300 \mathrm{~K})$.

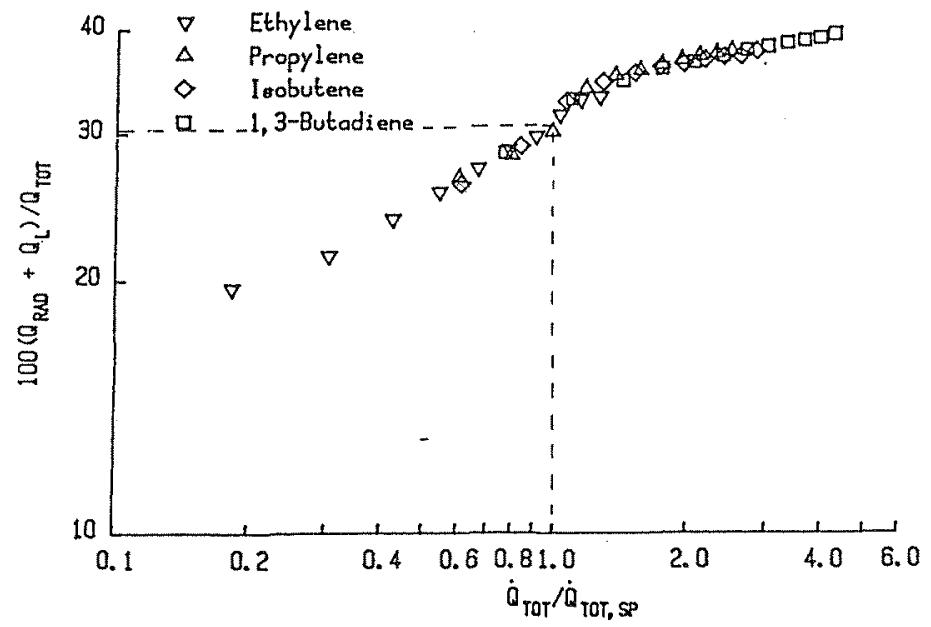

Fig. 5: Total loss fraction vs. total heat release rate normalized b the smoke-point value; for laminar diffusion flames $\left(\dot{Q}_{L}\right.$ 2.91W). For greater clarity only every third data point ha been plotted. Dashed lines indicate smoke point.

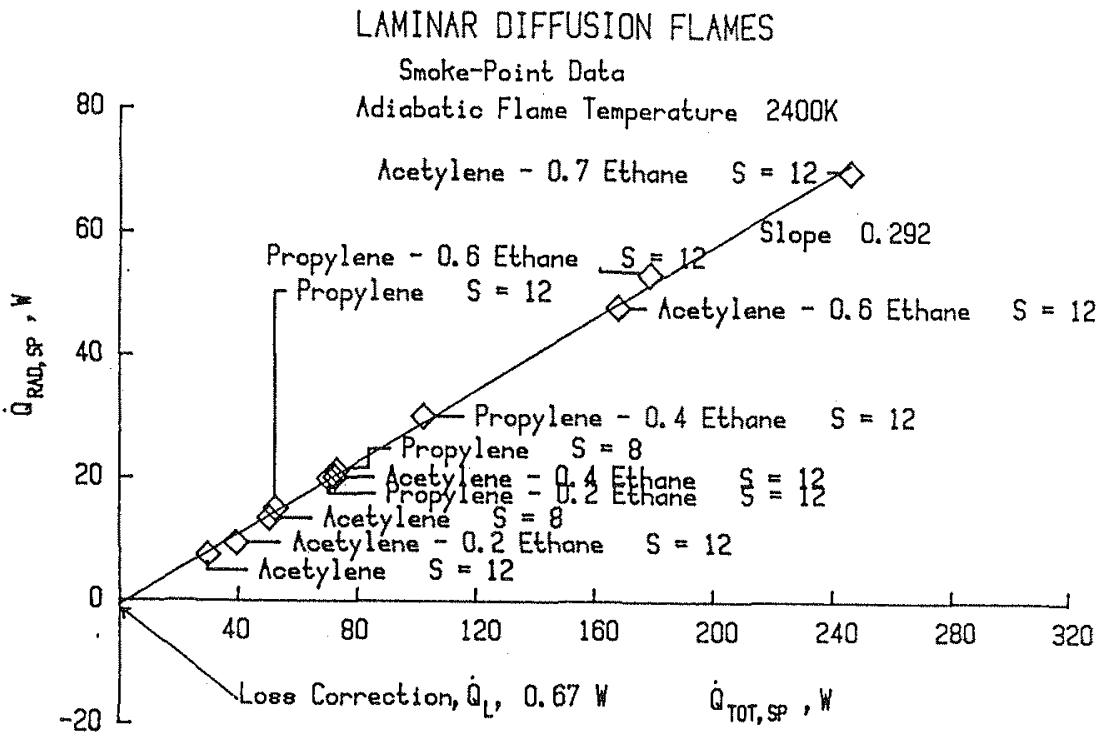

Fig. 6: Smoke point radiant output for a variety of fuel/oxidant combi nations having an adiabatic stoichiometric flame temperatur equal to $2400 \mathrm{~K}$. Here $S$ is the stoichiometric oxidant/fuel mas ratio. 
Eigure 6 shows the smoke-point radiant output for a variety of fuel/ oxidant combinations whose compositions are adjusted to produce identical adiabatic stoichiometrio temperatures equal to $2400 \mathrm{~K}$, but with a variety of compositions and stoichiometric oxidant/fuel mass ratios, $s$. It is apparent from this figure that the smoke-point radiant fraction is independent of the stoichicmetric mass ratio and fuel/oxidant chemistry at a fixed theoretical flame temperature. Similar results were obtained for theoretical flame temperatures of $2200 \mathrm{~K}$ and $2600 \mathrm{~K}$. These results are summarized in Figure 7. We thus conclude that the smoke-point radiant fraction from buoyant laminar diffusion flames depends only on their adiabatic stoichionetric flame temperature.

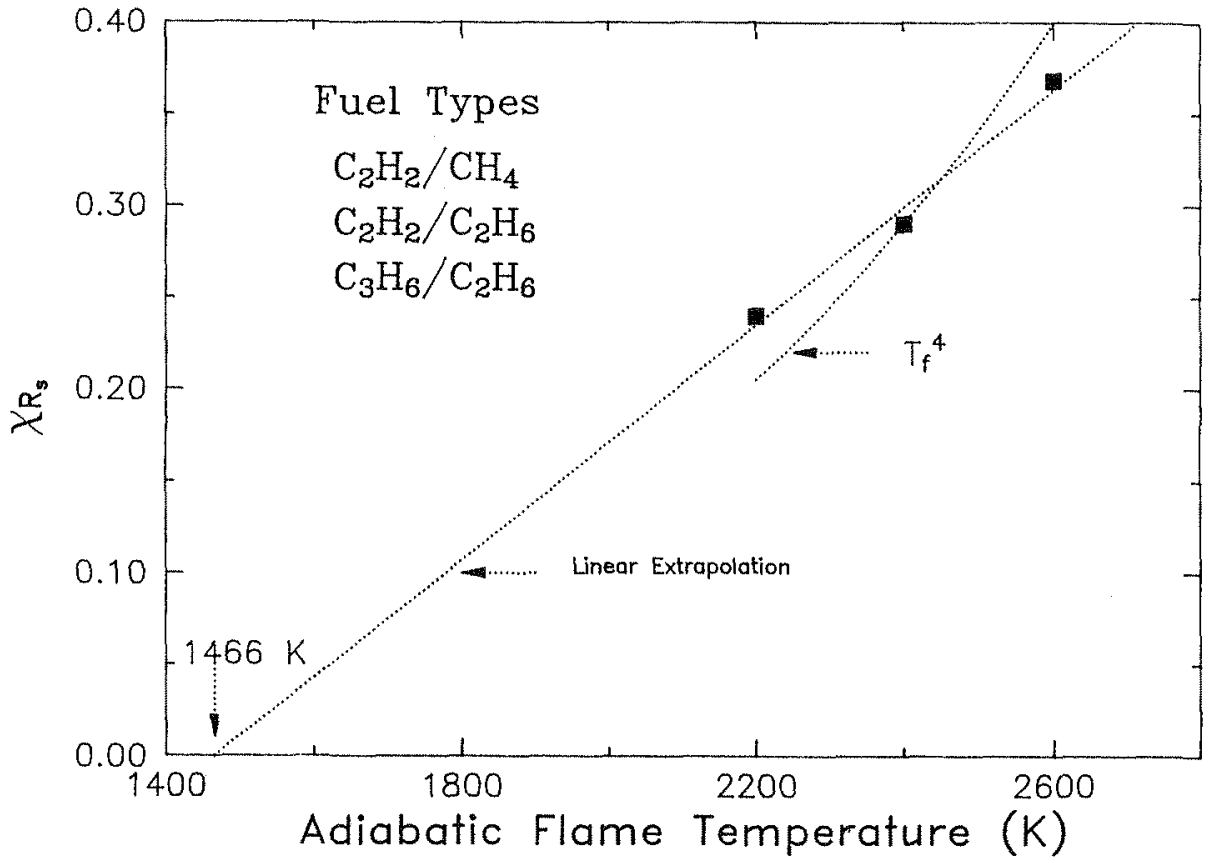

Fig. 7: Summary of smoke-point radiant fraction data for adiabatic flame temperature equal to 2200,2400 and $2600 \mathrm{~K}$. Note deviation from $\mathrm{T}^{4}$ curve.

d) Spot Absorption for Smoke-Point Flames - Figure 8 shows Olson's measurements of the mid-height soot volume fractions for a wide variety of hydrocarbon fuels burning in air at their respective smoke points. The abscissa is his so-called threshold sooting index (TSI) which is essentially inversely proportional to the smoke-point height. The sooty aromatic fuels on the right have high TSI values and correspondingly low smoke-point heights. Olson's faired-curve approximates our previous scaling predictions, Eq. 6,

$\left(k_{s}\right)$ smoke point ${ }^{-1 / 2}-(T S I)^{1 / 2}$.

Similar scaling relationships are obtained by Kent and Wagner(21). 


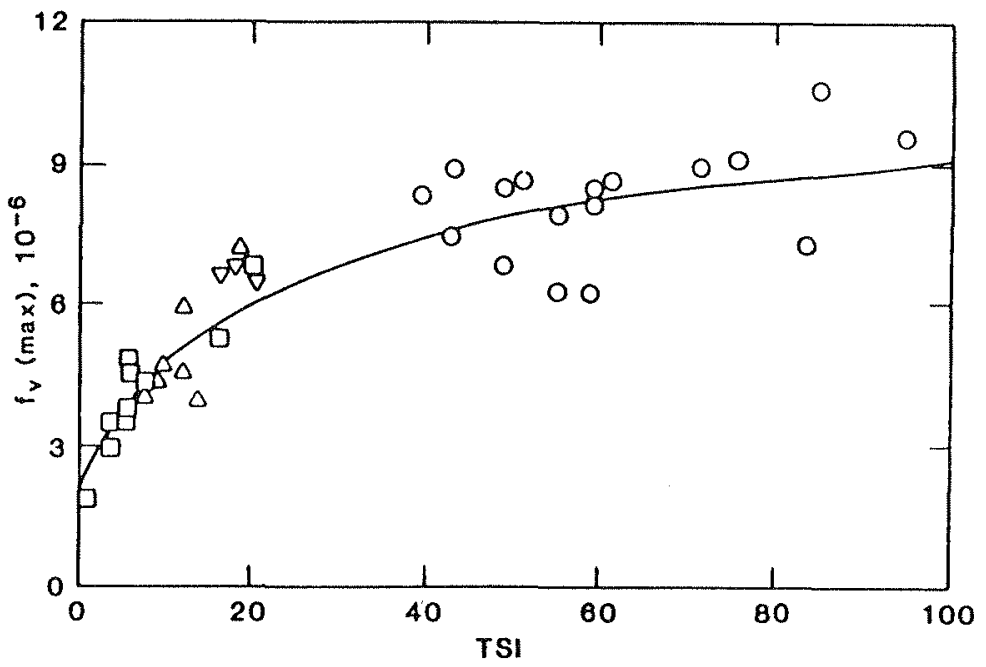

$Q=$ alkanes; $\Delta=$ alkenes; $\nabla=$ alkynes; $O=$ aromatics.
Fig. 8: Comparison of maximum soot concentration and soot threshold $i$ diffusion flames

e) Pressure Scaling and Soot Reaction Order - The scaling relatior ships can be extended to other than atmospheric pressure. During tr 1950 's Sohalla and MoDonald ${ }^{(22)}$ measured the smoke-points for a variet of liquid fuels over an eight-fold absolute pressure range. They four that the product of the absolute pressure and smoke-point height is pre cisely constant.

$\chi_{\text {fS }}{ }^{P}=$ const

Examination of our flame height formula (4) and the velocity and flan radius results ( $1 \mathrm{a}$ ) and (1b) yield the f'ollowing pressure dependencies

$\varepsilon_{\mathrm{f}}-\dot{Q}_{\mathrm{TOT}} \mathrm{P}^{0}, \quad \mathrm{r}_{\mathrm{f}}^{2}-\ell_{\mathrm{f}}^{1 / 2} \mathrm{P}^{-1}, \quad \tau_{\mathrm{f}}-\ell_{\mathrm{f}} / \mathrm{u}_{\mathrm{f}} \sim \ell_{\mathrm{f}}^{1 / 2} \mathrm{p}^{0} \quad(9 \mathrm{a}, 9 \mathrm{~b}, 9 \mathrm{c}$

since the product of $\rho_{f} \nu_{f}$ is independent of pressure.

Our previously established arguments, (following Eq. (7)), for radic tive fractions from smoke-point flames presumed a general similarity flame temperatures for smoke-point flames involving fuel/oxidant combinc tions with similar adiabatio stoichiometric flame temperatures. It : anticipated that, in a similar manner, these flame temperatures are ind pendent of pressure, so that from Eq. (7)

$X_{\mathrm{RS}}=\frac{\dot{Q}_{\mathrm{RS}}}{\dot{Q}_{\mathrm{TOT}}}-\frac{k_{\mathrm{sp}} \ell_{\mathrm{fs}} \mathrm{r}_{\mathrm{f}}^{2}}{\dot{Q}_{\mathrm{TOT}}}-k_{\mathrm{sp}} \ell_{\mathrm{fS}}^{1 / 2 / \mathrm{P}}$

after substituting from Eq.'s (9a) and (9b) for $\dot{Q}_{\text {TOT }}$ and $r_{f}^{2}$.

Now we can address the effective soot formation/oxidation reactic order by blithly assuming both the soot formation and oxidation rate have the same order, $\mathrm{n}$, and examine the consequences of the assumptior Thus defining a general soot reaction rate function $f$, one has 
$\frac{D k_{S}}{D t}=\frac{D\left(\rho Y_{S}\right)}{D t}=P^{n_{f}}\left(Y_{i}, T\right)$

where $Y_{S}$ is the soot mass fraction, $Y_{i}$ and $T$ are the $10 \mathrm{cal}$ compositions and temperature, while $f$ is independent of pressure. Invoking once again our general similarity assumption, we have

$\frac{D k_{s}}{D t}=\frac{k_{s p}}{\tau_{f s}}-\frac{k_{s p}}{\ell_{f s}^{1 / 2}}-\frac{x_{R s}{ }^{p}}{\ell_{f s}}-x_{R s} p^{2}$

where we use in sequence $\mathrm{Eq}$. (9c) for $\tau_{\mathrm{fs}}$ and $\mathrm{Eq}$. (10) for $k_{\mathrm{Sp}}$ and finally the empirical relationship (8) for $h_{\text {f }}$.

It appears quite likely that the radiant fraction $\chi_{R s}$ is independent of pressure although this has not been experimentally verified. If this is the case then comparison of Eq. (11) and (12) suggests that the effective combined soot formation/oxidation rate is second order in pressure. Upon reflection such a second order dependence would not be surprising for both soot formation and oxidation.

In the case of soot formation various proposed detailed chemical mechanisms $(25)$ all involve bimolecular exchange reactions so this result is anticipated. On the other hand soot oxidation in rich regions probaply occurs primarily by hydroxyl radical attack on the soot particles (24) which in itself is likely to be a first order surface reaction. However, the hydroxyl radical concentration is probably pressure dependent so that the actual controlling reactions for soot oxidation may nevertheless occur in the gas phase. Fenimore ${ }^{(23)}$ has shown that soot oxidation rates are very similar to $C O$ oxidation rates and they both occur in the same flame regions. A sequence of bimoleoular exchange reactions for CO oxidation must generate an extra free radical for each oxidation of a carbon monoxide molecule. For example, an overall sum of bimolecular exchange reactions might produce the result

$$
2 \mathrm{CO}+\mathrm{O}_{2}+\mathrm{H}_{2} \mathrm{O} \rightarrow 2 \mathrm{CO}_{2}+\mathrm{OH}+\mathrm{H}
$$

which preserves the total number of molecules on both sides. These resulting generated free radicals would then be available for soot oxidation.

The above discussion is presented with the intent of merely showing that it is possible that both the soot formation and oxidation processes can be controlled by second order reactions. Partial confirmation of this result could be obtained by adding to the fuel trace amounts of salts which are known to significantly increase the number of soot particles and soot surface area without altering the soot volume fraction. If the smoke-point of a fuel were essentially unaffected by the addition of trace amounts of salts, one might then conclude that soot oxidation rates in diffusion flame were controlled by gas phase rather than surface reactions.

\section{FLAME RADIATION TEST METHOD}

It is clear from the preceding discussion that a fuel's smoke-point represents its key measurable property which controls its flame radiation and consequent large-scale fire hazard. Smoke-point heights can be readily measured for gaseous fuels (fuel jets) and Iiquid fuels (wick bur- 
ner). Solid fuels present a more formidable challenge. They general: produce a protective char layer which induces transient burning. The require high incident radiant fluxes to induce pyrolysis. Such fluxt must not interfere with the combustion or any flame radiation measure ments. The pyrolysis vapors must be prevented from any unwanted thermi cracking through contact with heated surfaces before entering the diffi sion flame. Finally, the apparatus must be convenient to operate ${ }^{(26)}$.

Several investigators are now exploring possible smoke-point tes methods. Figure 9 shows an apparatus being assembled at FMRC. It iss lates the pyrolysis chamber from the flame region and uses a protecti. gas shield to prevent unwanted surface heating of the pyrolysis vapor before they enter the flame.

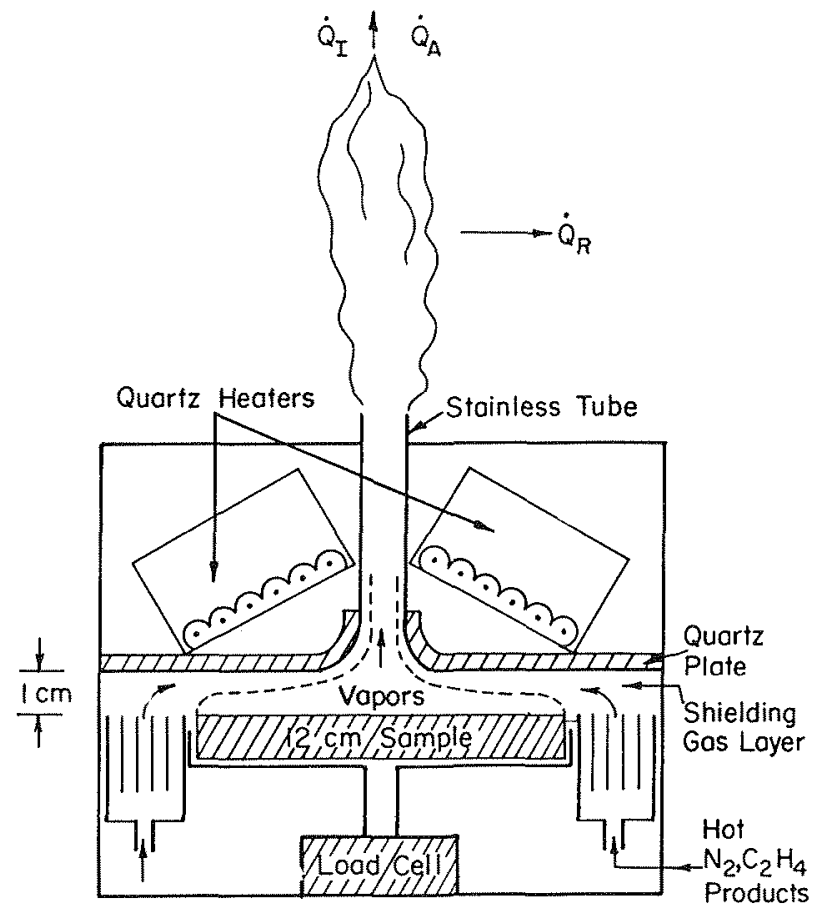

Flame Radiation Test

Fig. 9: Flame radiation test apparatus being assembled at FMRC

\section{CONCLUSIONS}

We have brieply reviewed a few of the important avallable materi. flammability tests. At present we do not have available a suitable te: for inferring the radiative properties of $f l$ ames produced by solid fuel; These flame radiation properties unfortunately control large-scale $f i$ hazards. Careful measurements of the radiation from large-scale turbi lent flames show that flame radiation is closely correlated by the cla: 
sical smoke-point values. We next summarize many recent discoveries on the scaling of soot formation and radiation from buoyant laminar diffusion flames. The numerous correlations suggest that a fuel's smoke-point plays a fundamental role in controlling flame radiation and smoke output. It may also control the emission of toxicants such as unburned hydrocarbons and carbon monoxide. We have pointed out some of the problems to be overcome in the development of an apparatus for the measurement of the smoke-point of solid fuels. A possible apparatus is presented. Finally, it is apparent that our empirical understanding of flame radiation and soot-formation is advancing very rapidly and is now available for supporting the development of a general scientific understanding and models of flame radiation processes.

\section{NOMENCLATURE}

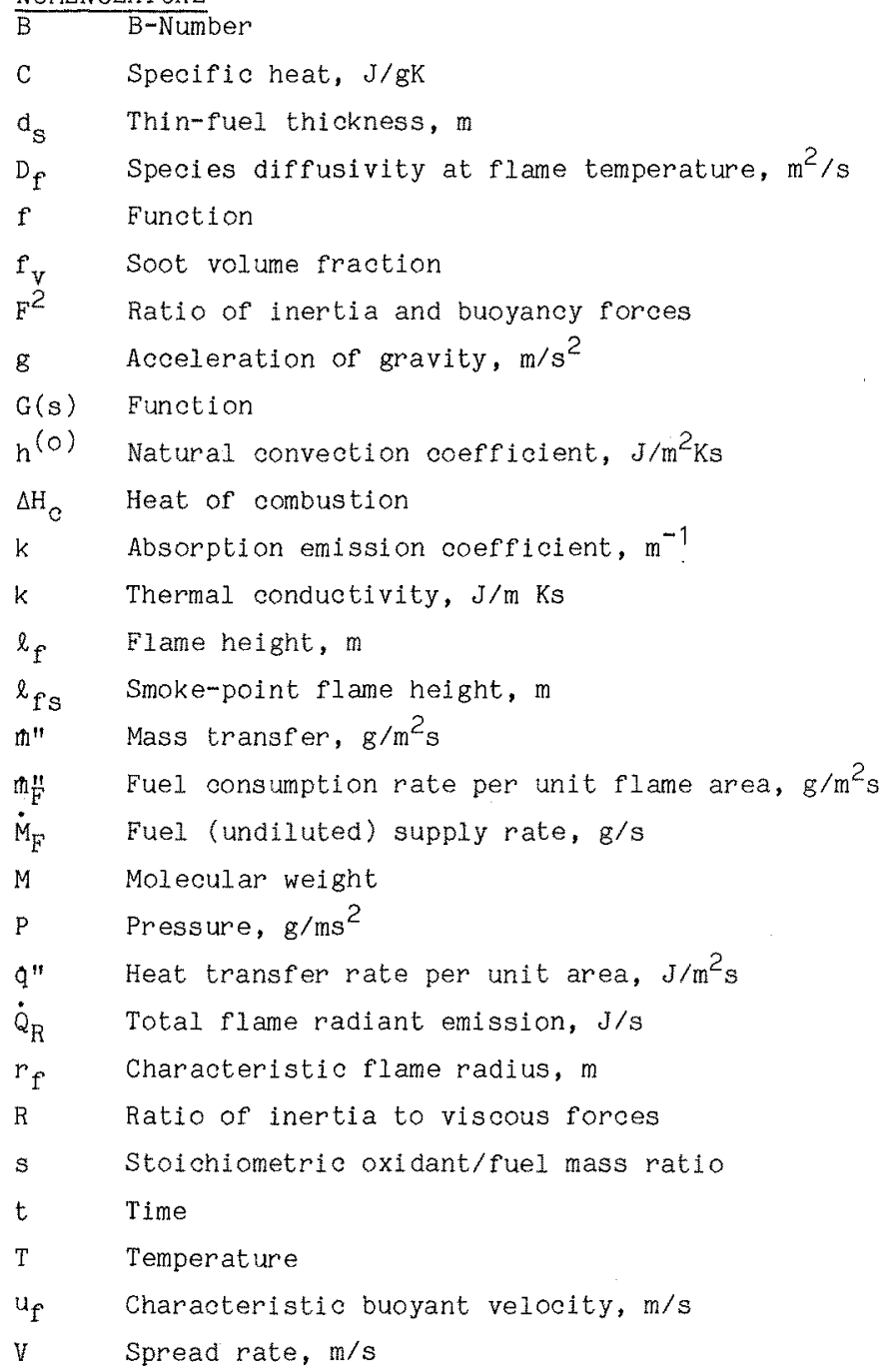




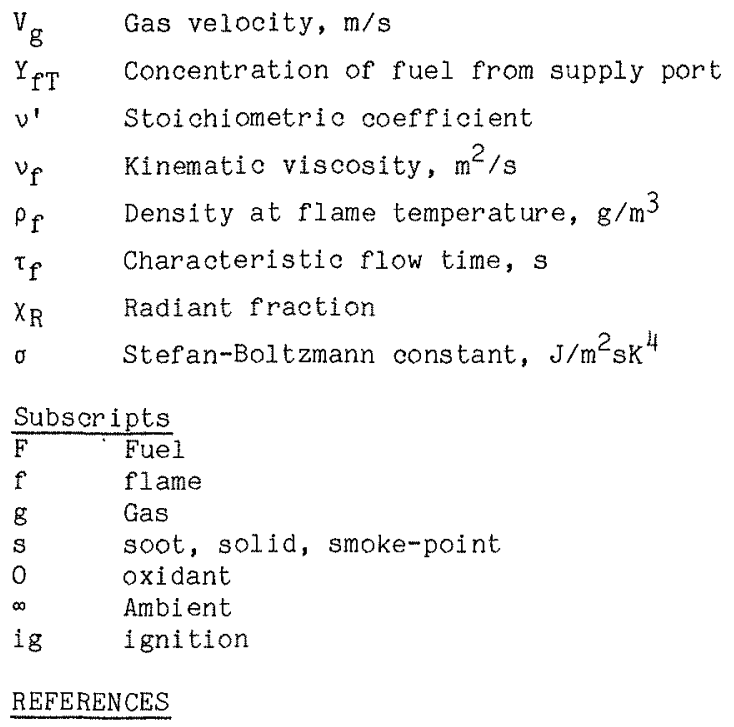

1. Pagni, P.J. and Shih, T.M.: "Excess Perolycate," Sixteenth Symposiul (International) on Combustion, pp 1329-43, The Combustion Institute Plttsburgh (1976)

2. Delichatsios, M.A.: "Modeling of Airoraft Cabin Fires," FMR Technical Report RC84-BT-10, Factory Mutual Research Corporation Norwood, MA, (May 1984).

3. de Ris, J: "Fire Radiation - A Review," pp 1003-15, Seventeenth Sym posium (International) on Combustion. The combustion Institute Pittsburgh, PA (1979).

4. Modak, A.T.: "Radiation from Products of Combustion," Fire Researol 1. $(1978 / 79) 339-361$.

5. Grosshandler, W.L.: "Radiative Heat Transfer in Nonhomogeneous Gases A Simplified Approach," Int. J. Heat Mass Transfer, Vol. 23, pp 1447 $59,(1980)$.

6. Grosshandler, W.L. and Modak, A.T.: "Radiation from Nonhomogeneou: Combustion Products," Eighteenth Symposium (International) on Combus. tion, The Combustion Institute (1981)

7. Modak, A.T. and Mathews, M.K.: "Radiation Augmented Fires Withi. Enclosures," Journal of Heat Transfer, 100, pp 544-7, (1978)

8. Hottel, H.C. and Sarofim, A.F.: "Radiative Transfer," MoGraw Hill (1967).

9. de Ris, J.: "Buoyant Diffusion Flames," Heat Transfer and Buoyan Convection (D.B. Spalding and H.H. Afgan, Eds) pp 813-31, Hemispher. FubI. (1977). 
10. Santo, G. and Tamanini, F.: "Influence of Oxygen Depletion on the Radiative Properties of PMMA Flames," pp 619-31, Eighteenth Symposium (International) on Combustion, The Combustion Institute, Pittsburgh, PA (1981).

11. Markstein, G.H.: "Relationship Between Smoke Point and Radiant Emission from Buoyant Turbulent and Laminar Diffusion Flames," Twentieth Symposium (International) on Combustion, (in press).

12. Markstein, G.H.: "Measurements on Gaseous-Fuel Pool Fires with a Fiber-Optic Absorption Probe," Comb. Sci. and Tech., 39, 215-33, (1984).

13. Roper, F.G.: Combustion and Flame, 29, pp 219-26, (1977).

14. Schug, K.P., Manheimer-Timnat, Y., Yaccarino, P., and Glassman, I.: "Sooting Behavior of Gaseous Hydrocarbon Diffusion Flames and the Influence of Additives," Comb. Sci, and Tech., 22, pp 235-50, (1980).

15. Roper, F.G., Smith, C., and Cunningham, A.C.: Combustion and Flame, 29, pp 227-34, (1977).

16. Glassman, I. and Yaccarino, P.: Comb. Sci. and Tech., 24, pp 107-14 (1980).

17. Markstein, G.H.: Unpublished work.

18. Markstein, G.H. and de Ris, J.: "Radiant Emission and Absorption by Laminar Ethylene and Propylene Diffusion Flames," Twentieth Symposium (International) on Combustion, (1985).

19. Olson, D.B.: "Soot Formation in Synfuels," Aerochem TP-433, Aero Chem Res. Labs, Princeton, NJ (1983)

20. Markstein, G.H.: "Radiant Emission and Smoke Points for Laminar Diffusion Flames of Fuel Mixtures," Eastern Section of The Combustion Institute, (Dec. 1984).

21 Kent, J.H. and Wagner, H.Gg.: "Temperature and Fuel Effects in Sooting Diffusion Flames," Twentieth International Symposium on Combustion (1985).

22. Schalla, R.L. and MoDonald, G.F.: "Mechanism of Smoke Formation in Diffusion Flames," pp 316-24, Sixth Symposium (International) on Combustion, (1956).

23. Fenimore, C.P. and Jones, G.W.: "Coagulation of soot to Smoke in Hydrocarbon Flames," Combustion and Elame, 13, pp 303-10 (1970).

24. Neoh, K.G.: "The Study of Soot Burnout in Flames," Ph.D. Thesis, M.T.T. (1981).

25. Frenklach, M. and Clary, D.W.: "Detailed Kinetic Modeling of Soot Formation in Shock Tube Pyrolysis of Acetylene," Twentieth Symposium (International) on Combustion, (1985). 
26. de Ris, J.: "Flammability Testing, State-of-the-Art" Fire and Materi als (in press) also FMRC Technical Report RC83-BT-7.

27. Orloff, L., de Ris, J., and Markstein, G.H.: "Upward Turbulent Fir Spread and Burning of Fuel Surfaces," Fifteenth Symposium (Internć tional] on Combustion, pp 183-92, The Combustion Institute, Pitts burgh (1975). 